\title{
DELIVERY AND ASSESSMENT OF SMALL ISLAND DEVELOPMENTS
}

\author{
RICHARD MOORE \\ School of Engineering and Built Environment, Anglia Ruskin University, UK.
}

\begin{abstract}
This paper reports on an aspect of continual research into small island hotel and resort development. Inputted are crucial elements of a consequential literature review linked to an appropriately selected building project case study. The analysis of existing research relevant to the topic correlated concerns flowing from trends of rising tourist numbers set against demands for more unique locations. Concurrently, the main focus of this paper is evaluation of the planning, design, construction and operation of a new tourism resort located on an uninhabited coral atoll identified and considered predicted and actual performance outcomes. Significantly, this 5-year investigation critically reviewed measurable responses to ecological pressures. These were noted in the processes of assessment during and following an initial independent international third-party certification organization's auditor using a process-based development framework tool. A major driver for the research is the shared aim of several stakeholders involved in associated 'in time' studies. This is to ascertain the veracity of specific environmental, social and economic measures when implemented by resort developers and an associated facility management companies. Most actions of these parties are primarily a response to increasing emblematic relevance and exacting government-driven policies. However, many also view broader company (CSR) and community aspirations as factors crucial to the delivering of project sustainability. A primary objective of the broader research programme has involved the engendering of links between theory and practical implementation of sustainable development principles with the reality of development. Another and equally pragmatic consideration was to show and evaluate the use of process tools by those engaged in the planning, design, construction and eventual operation of hotel and resort developments. This activity is to determine their propensity to using performance framework models targeted at achieving sustainable development and improved ecological outcomes.
\end{abstract}

Keywords: Planning, design, management, operation, indicators, sustainability assessment.

\section{INTRODUCTION}

\subsection{Dynamic relationships}

To achieve the goals of sustainability and eventually improved ecological performance, total integration of total development processes is critical. Solutions arise out of the overlapping and integration of disciplines and expertise. Dynamic relationships on a macro and a microscale need to exist between inputs and outputs if the value of a natural and built environment is to extend beyond simple financial accounting. On offer is meaningful social and environmental responsiveness. Critical is the recognition that the development industry in all guises (particularly when allied to travel and tourism) affects more than most and holds a key position in the often-stated objective of progressing towards sustainable buildings, precincts and cities.

Sustainability is without doubt a complex subject; the term itself is often misunderstood and misused. For many, it appears to be no more than being environmental friendly or a mechanical means of responding to a government or regulators instruction. This very limited view must expand and give broader translation. Simply seeking, the reduction of energy usage, the possible recycling of waste and the protection of wildlife species will not aid in the progress towards achieving greater sustainable patterns of development. A more appropriate understanding is to recognize sustainability as a journey, which closely identifies with building undertakings, and aimed in particular at the 
crucial activity of project planning, design and management. Also important for all those involved is acceptance of sustainability as a dynamic process offering to simultaneously protect and enhance support systems being environmental, social or economic.

Added to this perception is the need to recognize that sustainability requires an awareness of how everything natural and manmade work. There needs to be an equal appreciation of what will be the likely effects and outcomes of development planning and design decisions and eventual actions on the process. Without this understanding, there can be no possibility of overcoming the many barriers to advancing a more integrative approach. This broader perspective and acceptance of responsibility by all involved in the process is paramount in achieving sustainable development and ecological performance improvements. These critically linked outcomes are part of a woven fabric, which influences all aspects of developing a facility. They are constantly challenging the industries involved to seek and pragmatically apply new metrics and solutions in the decisions being made daily particularly on the type of project represented in this paper.

In response, sustainable development has without doubt become the primary and most demanding business challenge. Whilst the business case for the delivery of sustainability principle is, all but proven many still waiver. However, demands are continuing to increase especially with national and state governments pressing industry and business to increase energy efficiency and reduce the damaging effects to the environment caused by greenhouse gas emissions. Many of these strategies seek to provide direction on how to shape and support cleaner environments and promote more effective land usage. Matching these aspirations are industry drivers towards smarter designs and construction practices aimed at improved resource utilization. Crucially also recognized is the critical factor of business certainty.

The first part of the paper examines the need for a coordinated industries response and research undertaken to understand the phenomena involved. The scale of economic activity represented by the development and travel industries results in major pressures on affected eco-systems creating environmental imperatives. This tension has caused some organizations to respond with new processes of design and supporting tools, which can assist with the creation of more sustainable developments. This transformation seems logical and self-evident, but it is presently constrained by a range of social and political barriers. For example, present building codes do not cover the full scope of factors pertaining to sustainability and usually focus mainly on energy.

A further impediment stems from issues concerning the need to reward 'best practice' sustainable master planning and design of precincts. The use of a specifically created framework can assist with overcoming these barriers by facilitating changes in the areas defined by Agenda 21 and geographical imperatives. Hence, the second part of the paper discusses the deployment of a tool in relation to a small island development, through its link to principles, new technologies and the building development process.

\subsection{Growing numbers of small island paradises}

UNWTO estimates that 900 million international travellers now leave their home shores every year [1]. The same organization predicts that this figure is set to increase to 1.9 billion by 2020, a potential growth of 3\% per annum. Regarding arrivals to Small Island Developing States (SIDS), the estimated number is 41 million as of 2011 [2] following an increase totalling 12 million over the previous decade. Importantly for this paper on interrogating these figures, changing regional representation is reflected with international arrivals in Australasia showing a 22\% increase in 2010 [3]. Crucially, the preceding figures do not include domestic tourists who are even more numerous [4]. Of further importance is on the noted estimations alone, which makes travel and tourism possibly the largest 
and fastest growing national and regional industry in modern economic terms $[1,2,5]$. Consequently, the resulting approximate $\$ 2.4$ billion earned from tourism everyday represents a capture of some $10 \%$ of the world's economy [3, 6]. Regarding SIDS, the annual revenue generated now exceeds $\$ 38$ billion. For several countries, their share can account for over 40\% of the nation's GDP [2].

Of significance is the recognition that SIDS in the Australasia region experienced some of the largest increases in tourism demand. Linked to this fact is a very common feature flowing from the analysis of data surrounding these figures and reviews of supporting national policies. Many restructuring and developing nations, particularly in the aforementioned region, have engaged with or have been using travel and tourism for some time as a means of undertaking socio-economic development [7-9]. Unfortunately, when strategic tourism stimulus links to the equally significant development and construction industry provision, the potential for ecological damage is immense [10]. Devastating ongoing impacts can include environmental vulnerability, overexploitation, energy dependency, population loss, social depredation, debt and economic volatility [11-14]. This has lead to extensive pressure on these two industries to ensure elimination or mitigation of the negative ecological impacts linked to tourism first [15] and secondly, the accompanying resort development and their on-going facility management [16].

Environmental issues and concerns are always a central consideration when linked to the preceding. However, sustainable development is now a further critical part of any ensuing development debate. Intrinsically linked factors, i.e. cultural, social and economic factors, attach to any discourse involving sustainability inputs and associated outcomes. Also added should be the growing concerns regarding the possible though often ignored impacts of declines in island populations and coastal climate change $[17,18]$. It is now an imperative to recognize that well-established and long-standing matters along with newer issues must direct and influence considerations of possible effects on small island coastal resort development [19-23]. Accordingly, connecting development with the principles of sustainability is a major prerequisite in contemporary tourism facility provision [24] and physical infrastructure delivery [25].

In the reviewed case study, this expansive view is of fundamental interest due to the islands unique nature and its location. Also of crucial importance were the developer's and managing operator's goals and objectives. Whilst actually predating the then high profile president of the Maldives international call [26] for the regional Tourism Industry to ensure environmental and cultural sustainability, they reflected universal messages. Paramount of these noted that whilst recognizing the fact that for many small island states tourism is an important economic component, this should not provide a distraction from the challenges associated with achieving sustainable development and improved quality of life. The complementing appeals mirrored a long held premise that even the slightest negative change in the delicate environment of specific island locations and nations could prove disastrous for all the parties involved [17, 27]. Also called for was the protection, preservation and revitalization of the important though often intangible cultural heritage and in particularly local practices and spaces [28].

Significantly, the general response by both government and industry at all levels has been mixed and somewhat deficient in pragmatic solutions. One cause often leading to inertia may be the long noted pluralism amongst the political-economic elite and a non-productive familiarity between voters and politicians [29-31]. A further and immediate issue is the continuing devolving of responsibilities to local authorities [32]. Many lack sufficient experience or the resources to ensure the appropriate controls needed for tourism developments. Essential factors recognized some time ago as needed for appropriate planning include efficient development implementation and effective organizational structures for the ongoing management of tourism and associated infrastructures $[7,33,34]$. Of equal magnitude is the continuing lack of certainty regarding practical meanings for sustainability and sustainable development [35-38]. Crucially, this absence of agreement ensures 
continuing uncertainty regarding what indicators to use [39]. Equally important when linked to this ambiguity regards how then to measure actual performance and outcomes [16, 25].

Unfortunately, all these aforementioned areas are still attracting ongoing debate leading to considerable confusion for those involved in actual development delivery particularly as some commentators now challenge the validity and influence of sustainability itself [40]. Persuasively, some suggest that good planning and design matched by a clear understanding of development risks aligned to appropriate mitigations will achieve many of the long-term ecological performance outcomes often sought. Understanding this conventional approach amongst existing consultants and regulatory authorities is common and therefore attractive. In addition, it lacks the theoretical complexity of sustainable development. Conversely, despite the aforementioned ensuing abstruseness, there are examples of progressive developers challenging the supply norms of tourism infrastructure. These best practice developments could assist the aforementioned statutory authorities to overcome the potential problems linked to their own shortcomings [41].

Furthermore, a growing number of companies are becoming fully aware that recognizing responsible environmental, cultural and social practices can translate into risk mitigation benefits for business, the environment and local and national community whatever pervasive doctrine is enjoying prominence. Innovative solutions when utilized by them are known to provide important efficiencies, cost savings and reputation benefits through variety and reliability of supply in terms of improvement in production and quality control [42]. These outcomes will ensure long-term appeal and success of a destination, which makes sound commercial sense [43]. In a major shift towards transparency (a prerequisite of sustainability and corporate social responsibility), some have opened their development planning, design and management processes to the scrutiny of internationally recognized accreditation standards [44]. Clearly indicating a willingness to reduce if not mitigates entirely the impacts of development. This is an essential response if such developments are not to become 'unregulated, formless or haphazard, inefficient and likely to lead directly to a range of negative economic, social and environmental impacts' [4, p. 125].

\section{RESEARCH METHODOLOGY}

The small coral island resort described in this paper is one where the outcomes of the third-party assessment are important for future attempts to undertake sustainable development in sensitive locations. This is because the certification process used a newly created Building Planning and Design Standard (BPDS). This framework process-based tool employs key performance areas (KPA) reflecting institutionalized pillars of sustainable development. The KPA indicators and measures find support in an exhaustive research approach and major database, respectively [44, 45]. The qualitative and quantitative information and data collected utilized for these KPA allies to benchmarking. The benchmarks used having been determined as appropriate when assessing if a resort was planned, designed and constructed in an ecologically sensitive manner. The framework encourages an integrated approach that when linked to an operational standard provides a connectivity that offers the opportunity for managing the resort's occupational phase operations in a similar manner. The KPA's indicators and measures reflect Agenda 21 principles and translate into a range of goals that include the protection and conservation of ecosystems, a diminution of local impacts by a reduction in resource use and an improvement in the local community's quality of life by equitable social and economic initiatives.

The preceding states assessment of sustainability uses KPA that allow evaluation of a project's progress towards improved ecological performance. The third-party accreditation processes consist of two stages: assessment and certification. Only projects that provide clear evidence during evaluation of a sustainability agenda aiming at achieving sustainable development will attain certification. 
The assessment process focuses on sustainable development contexts, KPA, indicators and measures used to review the predicted outcomes of a project. These primary context and KPA are:

- Master plans and design details

- Siting

- Building location

- Energy efficiency

- Water management

- Waste management

- Resource conservation (materials)

- Chemical use

- Wastewater management

- Stormwater management

- Social commitment

- Economic commitment.

Thus, the related indicators and measures evaluate a variety of tourism projects including individual resorts, hotels and mixed villa/resort schemes. All phases of development including planning, design, construction and operation are considered. However, postoperational evaluation (POE) takes places after the first full year of occupancy. Therefore, to help assess the total process sustainability appropriate construction management and occupational operation commitments, a number of critical documents are required to be prepared at the planning and design phase. These will need early submission for consideration and may include the building and infrastructure designs, landscaping codes along with biodiversity and ecology reports. Predicted operational energy and waste management policies and finally social and economic commitment strategies would be a requirement as well.

Efficient planning and design allows early identification of constraints and opportunities, streamlining the development process, leading to sustainable outcomes while achieving the project objectives. The independent assessment supports the project's multi-disciplinary planning and design team, in managing the process. As with any new approach, training courses for key members of a developer's organization or development team along with the possible engagement of an existing proficient consultant can further streamline the process and enhance the outcomes for the project. However, as the framework tool used here reflects the actual case studies and pragmatic project management approaches readily recognizable to most development managers, this is not essential. With this, a potential costsaving robust system of data collection to meet assessment demands has to exist. This feature is common to all the potential accreditation models now available to the industry. Evidence suggests that employing a process-based approach at the planning and design phase means the flow of detail needed for assessing a project logically reflects a development team's usual information delivery programme.

Importantly, a BPDS assessment uses comparisons with international industry best practice that often reflects location and site-specific constraints. While these can include national, regional and district limitations, only partial recognition of concessions, for example, issues linked to developing countries supply chain capabilities, is given. This is a justifiable approach as government development policies and international companies instigate many strategies and schemes, often use sustainable development visages as prerequisites for environmental, social, cultural and economic development. BPDS often responds to these demands by using enhanced profiles and data taken from actual and in some situations similar projects. This offers a more rigorous framework for the protection or enhancement of environmental areas such as waterways, natural site features, cultural and societal integration planning. It also provides more practical and tested means for reducing 
energy and water use along with greenhouse gas production. These economic focused factors provide long-term reductions of project operational and maintenance costs, which can lead to improved project viability and financial success.

Interrogation of the amassed details is by using spreadsheets created from the use of assessment principles to indicator process models that address input, process and output factors [25]. The spreadsheet output when matched to benchmarks enables performance comparisons with other developments particularly where similar processes are used. Also supporting this progression towards accreditation are generalizations based on expert opinion. Critically, many of the judgements regarding the goal of best practice outcome measures result from a database created from 10 years of recording operational performance. The values for the measuring of best practice outcomes is derived from extensive worldwide research into available and appropriate projects, industry surveys, engineering design handbooks, energy, water and waste audits, and climatic and geographic conditions.

The last two factors are important when considering location-specific issues, opportunities and actual performance outcomes. National and regional data per capita energy use, greenhouse gas and other emissions, wastes to landfill and water consumption where available provide other supportive information. The generic rules used to determine baseline and best practice levels as indicated in the standard involve information and data collected from a range of sources. However, if relevant sectorspecific case studies are not available for the type of development, designated region national averages are used to ascertain a baseline level. In these situations, best practice levels will be set at a minimum of $30 \%$ better performance than the baseline. Where case study or national data is not readily available for a KPA or an indicator, then the first development that benchmarks will have its results set as $15 \%$ better than baseline, which is halfway between baseline and best practice.

This background evidence and compensatory approach offers a normalization of expected performance values and overall outcomes expected from a development process. Linked to this detail will be specific industry, KPA benchmarking indicator substantiation. For example, wastes sent to landfill are measured in litres as waste bins are usually calibrated by volume as it has been found that the majority of operations do not have access to the disposed weight of the material. However, if weight is supplied, standard factors are used to convert weight into volume. These extensive sources and increasing benchmarked and measured planning, design and construction inputs from other case studies undertaken during a major research programme [44] give an unrivaled rigor in resort development assessment.

The information gathered not only aids preconstruction decision making but also determines ongoing operational ecological performance outcomes of the resort in environmental, cultural, social and economic terms. There are recognized research limitations that do have implications. As noted, the Maldives case study is one of a number of similar investigations into the total project management processes found in resort development. The analysis of the interlinked delivery phases provides insights into the inception, evolution, construction and eventually management of travel and tourism infrastructure. The large number of case studies in the broader research programme serves as a major evidentiary base to compare and assess the outcomes noted later.

Recognized is that indicator rigour requires constant augmentation. A feature of BPDS is that it updates best practice following each assessment. This is achieved through multiple case studies generating a cross case analysis, which is both descriptive and covers explanatory topics [46]. This option of updating recognizes that whilst each of the developments has their own context and perspective, the large number accommodates and overcomes the uniqueness and artificial conditions surrounding case studies alleviating concerns regarding case study research [47]. In doing so, they are able to provide a means to access highly pertinent information and understanding of real-life phenomenon. From the many outcomes, recorded, constructive observations along with viable 
implementation processes can be better-formulated [48]. The originality and value of the research recorded in this paper is the unique analysis of the correlations between desired development outcomes through increased cooperation, and actual real time process behaviour in terms of planning, design, construction and operational procedures. It also provides some early indication of continuing performance targets outcomes by linking seamlessly with the next phase of the total development process through POEs [49].

\section{THE CASE STUDY - A SMALL ISLAND DEVELOPMENT}

\subsection{Primary vision and objectives}

The selection and relevance of this case study [50] is due in part to the primary objectives of the owner/developer and the original facility-managing operator. The use of third-party operators is a critical aspect of many resort developments, as often owners do not manage the facility but pass operation unto a management company using branding to establish its market positioning as in the case study (i.e. Alila and Hyatt Hilton). In the study, both the owner and originally proposed operator (Alila) were seeking to ensure that all planning, design, construction and postoperational activities reflect ecologically sensitive methods [25]. While partly in response to strict selection criteria determined by the national approving authority, the two organizations' comparable approaches reflected their own visions and mission statements along with the use of an independent certification programme. Furthermore, a linked aim of all involved particularly those in the integrated development team was to ensure that the eventual operation of the resort would achieve ongoing ecological performance outcomes in environmental, social, cultural and economic terms.

These goals transferred to and remained the same for the eventual resort operator (Hyatt Hilton) introduced later in the process, providing a unique insight into the reality of tourism infrastructure development. This is a possible and critical area of conflict when circumstantial changes influence a dynamic process. However, for the case study the adoption of existing project goals kept the focus and direction of the sustainability agenda on track despite a major design change, i.e. water villas. On other schemes, such amendment to key stakeholders leads to confusion and conflict as major differences in environmental, social priorities and economic imperatives come to the fore against a likely reduced timescale.

With the preceding identified goals, aims and resultant objectives in mind, the case study has been subject to the assessment processes of the aforementioned newly developed BPDS [16]. This standard created for EC3 Global an international accreditation body, offers already described KPA, benchmarking indicators and measures along with a range of guidelines and tools. During assessment, all engage in assisting developers through the design and construction phases along with the eventual operational management of a project when responding to sustainability agendas in practice. The process-based framework specifically encompasses the planning and eventual building of tourism hotel/resort projects and associated facilities. The tool supports developers responding to ecological demands on infrastructure development and measurement in terms of impacts and eventual performance outcomes.

Significantly, with this engagement and the ensuing data, critical planning and design decisions taken have some certainty of success [25]. The tool also provides a means by which developers and other stakeholders involved in projects reflecting sustainability drivers can achieve recognition and reward when achieving industry best practice. This is because a central dimension of the tool is to offer positive outcomes such as social and economic equity, reductions in preplanning timescales and greater certainty in actual performance delivery. This concurs with the adjudged as strategically 
appropriate whole systems approach [51] needed when seeking solutions to multiple problems brought on by the large number of interconnections that exists within a complex process-based programme of considerable sub-systems [52]. All features commonly found on projects pursue a sustainable development agenda.

\subsection{Case study - development background}

The assessed resort is on Hadahaa Island, which is a small isolated and uninhabited coral island located in the central lagoon of the Gaafu Alifu Atoll Maldives. Ovular in shape, the island's land area is approximately $7.75 \mathrm{ha}$ (see Fig. 1). The island is some $405 \mathrm{~km}$ south of the Maldives main international airport at Male. The nearest regional airport is some 52-km distance. Travel from here takes approximately $60 \mathrm{~min}$ by speedboat. Virtually on the equator, the island has an equatorial day and night cycle climate of no seasons with unpredictable tropical showers. Two regional monsoons take place between May and October, and January and March. The island has a hot tropical climate with a temperature range of maximum $32^{\circ} \mathrm{C}$ and minimum $23^{\circ} \mathrm{C}$ rarely falling below $25^{\circ} \mathrm{C}$. Humidity is normally high though the surrounding sea does provide a buffer through cooling sea breezes. The island and the existing vegetation are relatively sheltered from oceanographic conditions and various wave forces. Of particular importance are the stands of Sea Trumpet and Sea Hearse that have ecological and cultural significance. There is abundant fish life in the lagoon and good coral cover; the island's reef is suitable for snorkelling. Again, it is worth noting that this climatic and ecological description of condition is important when reviewing predicted and actual performance outcomes set against location factors.

Also crucial are the economic components supporting the project. In the case study, the background was a \$(Aus) 40 million medium-sized resort creating 14 Aqua Villas and 36 Island Villas of which 20 have individual small pools. Of the two restaurants, opened one specializes in Maldives cuisine. The leisure concierge service provides access to all island activities and excursions most with a strong accent on cultural experiences. The developer and the facility managers of the constructed and operational project are experienced people who own and operate a number of resorts in the Asia Pacific Region respectively.

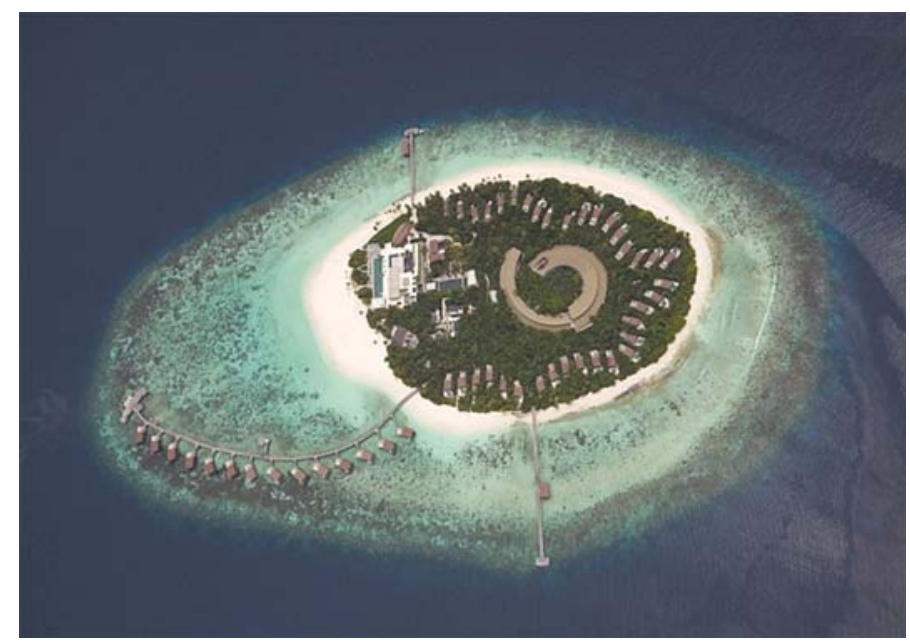

Figure 1: Hadadaa Maldives (Hyatt Park Hilton). 


\subsection{Overviews of accreditation standard, KPA, indicators and measures}

BPDS used the KPA, sector benchmarking indicators and measures to assess the sustainability of the resort's planning, design and construction management process and predicted outcomes. These are set at industry baseline and best practice performance levels, which face continuous review and changes over time as more assessed schemes provide ensuing data. The standard models are 'As Designed' case and a 'World Best Practice' case. The world best practice case considers what are both technically and financially viable efficiency measures and reflects whole systems thinking for that specific project with its cost and environmental constraints. The benchmarking follows a written methodology that defines default values in the event that the development documentation is silent as to specific planning and design elements of the total project systems. The default values are set at standard practice or regulatory requirements. For the as designed and world best practice cases, the standard tools calculate predicted use and outcomes over a year of full operation. It estimates, for example, annual energy and water costs and capital cost required to invest in the recommended efficiency measures and systems. The calculations include a rate of return on the investments. This indicator appraisal sets out the initiatives that if implemented will help a project achieve 'World Best Practice'.

At Hadadaa having satisfied all the criteria and requirements of BPDS, the development achieved certification by EC3 Global (Earthcheck) following an accredited Third-Party Auditor review of its processes and supporting documentation and in this case study, on site activity and actions [51]. This accreditation recognized that the resort represents industry best practice regarding process management and improved ecological performance for small island projects.

\section{ASSESSMENT OUTCOMES}

The following primary overviews, comments and outcomes emanate from the BPDS assessment. This sought to determine achievement of the principal objectives of the standard to facilitate environmental, social and economic sustainable design and construction and operational management of individual buildings and associated infrastructure. The overviews and reflections are supported by an array of pragmatic 'sustainability' priorities driving responses such as assessed community needs and equitable economic commitments to the vision of seeking process-based ecological performance outcomes that make the resort a leading example of small island development. The findings of the assessment reflect the structure of the tool and indicate the extensive range of inputs needed to achieve a sustainability and improved ongoing ecological performance.

However, the comprehensiveness of the following by no means represents the limits of what can be termed sustainable development. They recognize not only international standards but also specific location-driven measures that provide a realistic level of achievement for a developing small island nation. As will be noted, this does not mean acceptance of practices that are deemed damaging simply because they are the norm or difficult to achieve regarding best practice. The argument for this uncompromising stance is one of the development aspirations and specifically the international facility management company's expectations.

\subsection{Sustainable planning, design and construction management}

Sustainability planning and design documentation showed an approach that prioritized cultural integrity and environmental protection. Careful integration of villas and public facilities within the existing natural environment of the site ensured that they fitted in as unassumingly as possible to preserve the natural environment of the destination. However, an initial project appraisal including 
an operator interview regarding broad sustainability delivery objectives indicated the probability that possible sought for ecological outcomes were under threat. Primarily, this was due to a lack of indepth appreciation of sustainable development priorities demanded by a non-rating system. The later involvement of a dedicated local environmental sustainable design consultant and several other international consultants from Norway, Thailand and Singapore remedied the situation by strengthening and integrating the design and management team more fully during the early planning and design phase. Development team assistance was by specifically developed documentation showing how to interpret BPDS more holistic as well as technical performance requirements. They also had direct contact with the Independent Assessor who was taking part in the already mentioned broader research project.

When reviewing the project due, consideration was given to the issues of location and actual resources in the Maldivian Construction Industry. The location's scale and the difficulty in geographical access ensure a demanding market within to operate with respect to the local skills base, equipment and material sourcing. Despite these constraints, encouragement in the selection of local contractors and subcontractors with sufficient experience to implement 'green' design including sustainable construction in subsequent contractual agreements was noted. Subsequent evidence submitted during the construction phase showed that an experienced local contractor was employed. This was important as changes to site management practices and activity needed to be implemented following the independent Assessor's intervention. The immediate response to criticisms indicated a strong desire to conform with a more developed industry's standards of project control.

An essential aspect of any project is the design approach and sustainability policy. The essential elements (which provide a set of potential guidelines for island development) of the project's policy were seen in a range of supplied documentation. They included sustainability goals and vision integrated into the design brief, which linked conservation, community and commerce in one integrated ecological cycle. This aimed at achieving sustainable commercial success with businesses identifying conservation and community as key priorities. An environmental brief existed including a well-structured and comprehensive environmental impact study (EIA). The EIA provided an impact assessment checklist, guidance and positive responses to issues, which lead to improved design outcomes. The provision and integration of this document into the development process took place during the feasibility stage. Crucially, a commitment was given that following the adoption and implementation of the planning and design framework on completion of the resort's construction, the use of the EC3 Company Standard would be adopted. This meant monitoring and assessment of the resort's operational efficiency, particularly with regard to its environmental and social performance taking place. Other important features seen were the interdisciplinary and eventually coordinated approach involving all design and construction professional and operational stakeholders. A cost plan included budgets for sustainable strategies and measures as non-negotiable elements. This supported a contractual agreement with the resort builder, which included the use of BPDS processes and sustainable development recommendations. Finally, an operational management statement was created for postconstruction assessment, operational control and continual improvement of environmental and social performance.

An extensive and comprehensive EIA (an aforementioned statutory requirement in the Maldives) influenced the revised siting of public and service buildings. This reduced possible negative impacts and helped in the creation of positive effects on the natural environment. The location and design changes recommended created a better use of the islands' amenities particularly improved high value scenic-island and sea-views and reductions in building area land coverage. In a further response, revised designs for villas and resort facilities included larger open areas and less mechanical intervention. Major sustainability outcomes that included the site achieving a very low building and 
infrastructure coverage area (approximately 20\%) resulted. This gave a very high degree of permeability providing extensive opportunities for biodiversity replenishment and organic material collection. The low building area to site ratio also provided design opportunities to achieve siting gains with high degrees of privacy and minimal disturbance of native vegetation. This, in turn, means the site can offer large designated zones for biodiversity protection. These areas account for considerable tracts of new landscaping and those retained in their natural state.

The EIA also encouraged that the resort accommodation buildings align to achieve better access to passive climate interventions of tree shade and prevailing sea breezes. This approach provided good micro-climatic orientation and built environment efficiency. The design of areas around the buildings enhanced the environmental qualities of external spaces through using landscaping for microclimate control and zonal planting for efficient maintenance. To help maintain and improve the island's existing plant, gene pool selection and re-introduction of native species were undertaken.

The importance of managing air quality protection and noise control flowed from time progress photographic evidence. This showed that by eventual utilization of the EIA recommendations, reactive management actions and instructions reduced the environmental impact of building activities on site. Similar recorded evidence exists for the reduction of air and noise pollution from construction processes. This is a known problematic area where inexperience or limited management skills and training create on-site issues that can lead to major pollution impacts. The construction process received considerable monitoring and input from the consultant team and the auditor, all aimed at preventing incidents affecting resort accreditation.

The Standard offers a total process framework for assessing the construction management strategies proposed for the development. The project when assessed during this phase identified areas that benefited from an integrated approach, in particular, adherence to all local laws and regulations. Crucially, the EIA discussed all these relevant laws and regulations and the developer and constructor conformed to them, which was a prerequisite of BPDS. The site also benefited during the construction phase from the use of the regulatory approved EIA, which is required to provide a checklist of possible negative and positive impacts along with an outline of monitoring programmes. The implementation of which must happen during the building and operational stage and specifically before the resort begins to receive guests. They include active mitigation site management during construction and strategies for material storage, tree and vegetation protection.

Concurrently, the construction processes are influenced by location and design. They have to reflect the reality of the Maldives economy, manufacturing industry and practices of its building industry. Of significance is the importation of virtually all building materials to the Maldives, including sand and even in some cases water. While most building items are available locally, they are manufactured in very small quantities and are expensive. Few items, therefore, are purchasable from the capital in the quantities needed for most modern projects. The contractor internationally sourced and imported the bulk of items used on the project. Of interest is the fact that delivery vessels went straight to the island instead of discharging cargo at other ports avoiding double handling. This was faster, more environmental-friendly and economically highly efficient.

The manufacturing sources are India $(1000 \mathrm{~km})$ for sand, aggregate and reinforcing bars. Cement comes from India and Indonesia (1000 and $3400 \mathrm{~km}$, respectively). Certified timber comes from Malaysia $(2900 \mathrm{~km})$ with plumbing materials coming from Singapore, Malaysia and Thailand (3300, 2900 and $3600 \mathrm{~km}$, respectively). Transportation of materials sourced from local companies utilized locally constructed vessels. Whilst acknowledging the embodied energy and emission costs borne by these practices, considerable offset gains from the wider social and economic benefits derived from the supply chain processes are employed (see social and economic commitments). 
Regarding the actual island site, the EIA again provides guidance on measures to mitigate or lessen the impacts of building works on its environment and surrounds. The following are measures noted in the design documentation, the EIA report and observed on site. Actual construction involved an experienced local builder with labour and basic building materials sourced locally wherever possible if quantities allowed in the case of the latter. Minimal reef clearing allowed for jetty footings. The eventual structure accommodated barge or vessel unloading. All building works to construct the jetty and Aqua Villas were carried out during extreme low tides minimizing silt disturbance. No temporary sand roads were permitted on the island. Minimal site clearance, particularly of existing plants and trees, took place during construction with clearing only undertaken to accommodate the footings of villas and other resort buildings. Several villas re-positioned during construction works ensured further tree preservation. Temporary structures were placed in areas of minimal plant growth reducing clearing or damage of existing vegetation.

Material storage plan was implemented to protect island, i.e. steel bars in the stockyard lay on raised wooden planks to avoid direct contact with the soil and covered with plastic or canvass for protection against the elements and runoff. A waste management plan (WMP) was implemented with non-compostable waste disposed of by using waste disposal units during construction. Hazardous waste was transported to an off island disposal site. Extensive temporary housing and facilities were constructed on-site for the building work force. Temporary construction power was set via generator sets (removed following end of building phase). Sewage treatment plant was the first programme activity constructed. No coral used as a building material and no sand mining, movement or dredging on or around the island allowed. All temporary trenching was prohibited with only one trench dug for the entire resort water, power and sewer infrastructure. All data, phone, TV, fire and other low-voltage cables were run through conduits placed in the same trench for later installation in same trench.

\subsection{Energy efficiency, conservation and consumption}

The use of a 'whole of systems' view for designing systems for reducing energy consumption at the resort formed part of the resorts reduced energy consumption vision and is reflected in the actual building design documents provided. A key focus at the design stage is to ensure that adequate planning was undertaken and related decisions taken to control and reduce energy consumption. Details outlining the overall energy consumption during construction of the resorts' buildings and infrastructure also reflected a desire to reduce energy usage during actual construction. The resort tackled energy efficiency and conservation through a range of approaches. The resorts method of power generation and energy uses benefited from being subjected to an energy audit. The EIA report and subsequent amendments to initial designs also meant an overall improvement in predicted energy use. Whilst the primary energy source for the project is via three diesel generators, power saving is through demand management by automated control systems.

Further, the generators are new breed high-speed efficient models with very low emission ratings and minimal skill maintenance requirements. This last area is an essential consideration for any SID given the high cost of imported expertise when selecting essential operational mechanical and electrical plant and equipment. Other means of reducing demand for heating, ventilation, air conditioning and lighting are by using passive design features in the villas and resort facilities. These minimized the need to depend on a high usage of the HVAC systems in the villas. Some of the sustainability approaches and measures adopted along with major recommendations implemented included appropriate design for the tropical climate of the island particularly orientation and the limiting of air conditioning. This last measure through naturally ventilating areas in outdoor public buildings and 
cross ventilating all villa room interiors provide natural cooling and sufficient fresh air intake in rooms. This also helped to minimize $\mathrm{CO}_{2}$ emissions levels.

Other features and measures included appropriate openings and glazing ratios to wall areas and deep roof overhangs and shading to windows to reduce heat from sunlight. Natural day lighting is used to minimize artificial lighting of all habitable rooms and covered areas. Light colour schemes to walls reflect heat with reduction of conducted heat by using materials with low thermal transmittance value. Other passive measures for resort facility buildings include the use of high roofed areas and open ceilings and training programmes to increase awareness of staff and guests on energy conservation.

Whilst active measures are used at the resort, the design of the heating, ventilation and airconditioning system are based on the integration of performance efficiencies in the buildings' envelopes. These include major facilities HVAC system having flexibility of operation via a mixed mode control system allowing selection of either natural ventilation with ceiling fan assistance or air-conditioning. Air-cooled split-type AC units are selected for their energy efficiency. Further, the use of heat recovery from generators for water heating and sizing to accommodate demand cycles for fuel efficiency. Efficient lighting systems, such as low mercury fittings with photosensors to carefully positioned external lights, specified. Clustered circulatory pumps were used to maintain water temperature and reduce heat loss. Positive ventilation to kitchen areas discharges heat and odours but also maintains air quality for staff. A public swimming pool strategy to reduce energy demand was implemented with the use of an autosalt chlorinator system to minimize the use of chlorine, associated pumping and filtration. Low-voltage demands resulting from energy strategy reduces the need for transformers, high-voltage switchgear and power factor correction capacitors.

Furthermore, major improvements in energy efficiency and conservation flow from the installation of a waste hot water adsorption chiller. An expected saving of 400,000 kWh/year hot water production was based on heat recovery from the resort generators. There is also a potential saving of $400,000 \mathrm{kWh} / y e a r$ in the main kitchen with the installation of an air-handling unit able to achieve a $50 \%$ energy recovery. Assessment of this performance and other outputs form part of the POE using the EC3 Global Company Standard. These overall, energy efficiency and conservation measures are likely to reduce gross energy consumption by $30 \%$. The $\mathrm{CO}_{2}$ reduction estimate is 0.43 tonnes per guest per night per year. With an estimated 20,000 guests per year visiting the resort, this will achieve a significant reduction in greenhouse gases. These figures receive clarification later with POE data submitted following an assessment using the already mentioned Company Standard.

\subsection{Water usage, consumption and conservation}

The overall efficiency of potable water usage, promoting reductions without compromising the longterm operation of the resort, is part of the development's vision. Minimal consumption of potable water for construction activities was a primary target and reflected in the building and infrastructure design and construction practice recommendations. Whilst the EIA notes that the groundwater lens thickness, recharge and sustainable yield limits are good, there is no island ground water abstraction for resort construction or operational use. Potable water supply uses the methods of a reverse osmosis desalination plants supplemented through rainwater collection and storage. This desalinated water will be used for the entire domestic potable water system. To prevent any adverse effects of concentrated brine discharge, dilution treatment is undertaken prior to any release. Swimming pool water is supplied from this source. Demand reductions for water are achieved and maintained using water efficient appliances in public toilet facilities, bathrooms, laundry and kitchen. A hydro-pneumatic distribution system with booster pumps to enable uniform water pressure throughout the island has 
been designed and installed. Gardening water will not be connected to the domestic water system and drip irrigation to reduce water consumption by $50 \%$. Irrigation of natural vegetation and landscaped areas will also involve the use of recycled water. Storm Water is gathered using rainwater harvesting from the resorts' roof areas and is eventually stored in large rainwater tanks. This primary collection is by small underground tanks with small automatic pumps for directing water collected into larger above ground storage tanks. This approach also restricts the need to use desalinated water.

Mitigation design measures for the waste water system provides on-site treatment using nonchemical means and planned disposal arrangements as noted in the EIA and by the ESD Consultant. Reductions are also through the design of building wet systems, processes and a strategy for use of wastewater for recycling purposes. For waste water, there is no direct sewerage discharge into the ground so as to prevent any groundwater contamination. Treatment of waste water is dealt with by the comprehensive WMP. An on-site waste water treatment plant is provided with excess sludge used as a landscape biofertilizer.

\subsection{Solid waste production, chemical use and resource conversation}

There are major operational reductions recorded in solid waste generated and disposed of by the resort achieved through implementation of a comprehensive on-site 'Waste Management Plan', which includes recycling and monitoring. However, there were only limited reductions achieved in solid waste generated during the construction phase. Whilst the design and process management teams actively sought them, this area proved problematic due to the island's location and resort building needs. Management responses during the construction phase were positive though somewhat limited and remained challenging particularly regarding storage prior to disposal. On a more positive note on the EIA and design, responses did help reduce consumption of natural resources and impacts on the island's ecosystem and biodiversity. Achieving reduction in the overall consumption and impacts came first through the nature of the development and secondly by agreements with the local community regarding materials used and on-site activity and actions.

Regarding solid waste, the WMP also integrates the collection, treatment and disposal of all solid waste generated on the Island. A hierarchical approach based on internationally recognized practices involving reduction, reuse, recycling, recovery and residual management has been adopted. A revised plan was established for the island during construction and resort operation following early assessor criticism of the control exercised during initial site operations. The outcomes reflected the willingness of the development team to ensure measures ensued, which not only helped achieve certification but also provided a clear statement of intent during the operational phase. These included waste management principles written into construction and operational requirements. Solid waste was collected every day with segregation of waste into the appropriate physical equipment installed. The equipment included a bottle crusher, a compactor and a high-temperature incinerator. Operational management measures were introduced later to minimize waste generation include office practices, staff training, guest awareness, education, signage, bulk and refillable purchasing policies. Domestic waste including kitchen and guest food waste were composted or incinerated. Leaf waste and mulch from gardening activities composted for use as biofertilizers. Onsite in house drinking water bottling facility, using glass bottles minimizing waste amount of plastic bottles, etc. Waste generated from maintenance activities were treated in strict accordance of the nature and type of waste, i.e. all cleaning rags to be incinerated. Planned maintenance programmes for equipment, furniture, buildings and infrastructure were implemented.

Landscaping is a crucial element of the islands development and documentation clearly showed the importance given to this area. Sustainability measures included a comprehensive and very 
detailed landscaping and tree protection strategy and implementation plan. This included protection guidelines regarding clearing, temporary structures and building location. Large trees around guest villas and other infrastructure left untouched with no undergrowth clearance from setbacks or nonconstruction areas. No exotic plants introduced and a replanting programme for native species implemented including an extensive planting of ground creepers throughout the island to encourage vibrant terrain cover.

Mosquito and Gypsy Moth eradication measures were introduced on a regular basis using a nonchemical means of pest control where possible. Other chemical use involves only biodegradable chemicals specified for cleaning and laundry operations with the use of CFC free gas in freezers and refrigerators banned as per international requirements.

For resource conservation underpinning, all the proposals regarding physical delivery protection will be an Environmental Management Plan (EMP), which whilst implemented during construction is used as a major tool for addressing the postoperation of the resort. A part of the plan is for longterm monitoring of areas that include energy and water generation, solid waste generation and disposal, wastewater generation and disposal, infrastructure development, including coastal development, staff and guest activities and marine and terrestrial fauna and flora.

The primary aims of the EMP are an achievement of high standards of environmental conservation and protection to obtain ecological certification for the resort by an internationally recognized standard of environmental management. The utilization of environmentally sound products and materials for resort development and operation and assisting nearby islands manage environmental issues such as beach erosion and solid waste management. This aim was supported by increasing environmental awareness on nearby islands, of resort staff, tour operators, service promoters and guests. All of which contributes to national efforts for conservation of biological diversity, integrated coastal zone management, solid waste, and sewage waste management and sustainable tourism development. To meet this and other commitments which achieve continuous improvements, the resort has appointed a resident marine biologist and an Earthcheck coordinator who is responsible for identifying environmental risks, recording and monitoring performance through benchmarking, whilst driving the environmental and social initiatives undertaken at Hadadaa.

\subsection{Social, cultural and economic commitment}

Planned positive, productive and sustainable contributions to the local community are already evident in the long-term operations staffing requirements. Also, short-term construction employment and training opportunities are translated into a large social and economic benefit for the local community. The continuing employment opportunities at the resort and environmental initiatives provide an ongoing commitment by the resort owner and operator.

Regarding influences and benefits, the standard normally makes no comment on client developer decisions to secure or promote particular development land; however, the manner undertaken to secure Hadadaa Island is of broader interest. The transparent procedure outlined by the Maldives Government documentation was followed to initially place a bid and secure the right to develop the island clearly influenced project outcomes. The strict tendering criteria indicated that bidding to develop the island was an expensive business proposition with no guarantee of success in the tender process. Further, initial briefing of professionals such as architects, landscapers, mechanical and electrical consultants and building contractors had to involve significant environmental considerations to satisfy government regulatory requirements. For example, proposed buildings had to be suitable for the environment on the island, appropriate in building terms and positioned to enhance the natural features of the island. An integrated and cohesive approach adopted by the development 
team assembled in response to the challenges of the comprehensive submission to secure the winning development bid achieved these requirements.

As to traditional respect despite the island being uninhabited and having no existing structures, a unique mixture of local traditions influenced the resorts development concepts, actual construction management and benefits in responding to them. Contemporary in nature, the resorts planning and design philosophy respected local island architectural character and practices. An acclaimed Singapore-based architect interpreted these in both form and function. Architectural blueprints guided meaningful on-site impact studies prior to building implementation. In complementing the spirit of environmental stewardship, the design minimizes disruption to corals around the island and promotes rainwater harvesting. Other concepts preserve and reinforce the existing foliage of the island with a waste treatment plant ensuring minimal island pollution.

This commitment of the total development management team regarding respecting local traditions and customs was very evident. Interviews and responses to specific questions showed the influences of this important consideration on their decisions throughout the process. Whilst the island was uninhabited and, therefore, local community needs are somewhat difficult to assess, respect for local architectural character and a major drive to minimizing impacts on native land and population have underwritten the team's approach. Construction and operation of the project have involved local inhabitants, many of whom have and continue to work on the project.

Examples of this sensitivity included a design that attempted to reflect the local environment with regard to the scale, materials and texture of the buildings. Local consultancy firms for structural engineering and quantity surveying were commissioned. A local civil, building and labour contractor undertook the major construction works. All of the construction employees accommodated on-site with transportation to other islands made available when necessary. The pre-opening management team primarily worked in a Male office, accommodated in very close proximity of the design team office. This and the preceding measure were seen as a means to reduce environmental impacts related to personnel transportation. Salary levels are at least $30 \%$ above national averages for employment in the relevant category/skill. The level of staff accommodation and standard of food provided were substantially better than on other resorts when under construction or postoperational.

Community initiatives involved celebration of local Muslim festivals such as Eid and Ramadan. During Ramadan, modified restaurant hours accommodate prayer times with special meals provided to meet the fasting requirements of staff. Local programmes to support local crafts and artisans initiated. The resort provides special support to an existing programme of collaboration and exchange between local and foreign artists by providing the space for exhibition of local and foreign arts at local islands and technical means for the creation of new pieces on the spot. A programme to run English classes in a local school on the nearest inhabited island is being created. The resort is looking to start educational programmes for local youth related to hospitality. Educational staff programmes to include Cross Culture Training. There will be awareness programmes to inspire and assist communities to 'clean up, fix up and conserve their local environment' through carrying out initiatives ranging from waste removal and tree planting to water and energy conservation (this note should be read in conjunction with the previous commentary regarding the resident marine biologist initiative). Employees were trained and employed with specific roles regarding environmental protection, conservation and improvements. A purchasing strategy of buying where possible all the resorts' foodstuffs, goods and services from local companies.

Economic initiatives include the resort acting as a provider of much needed community support to the local villagers through medical and employment opportunities. These initiatives aimed at addressing the low employment and income levels of the atoll. For example, the planning, design and construction phases generated an estimated 180 temporary employment posts with the operational 
resort providing 181 fulltime employees. It is aiming for a local staff percentage of $80 \%$. Of interest is the sensitive linkage of economic development to cultural respect. Due to local Muslim culture, expatriates are required to be employed food and beverage positions related to alcohol (sommelier and bartenders).

\section{POST-OPERATIONAL EVALUATION}

\subsection{Initial and continuous measurement and improved performance outcomes}

As noted, the BPDS assessment standard is primarily a planning, design and construction focused tool. However, it recognizes that decisions taken at the early stages of the development process will have profound impacts on the operational performance outcomes. Research has identified that all the major third-party models of which BPDS is one employed on projects are primarily recursive early development phase tools created to encompass immediate project facilities and infrastructure. Fundamentally, they are 'principles to indicator' assessment tools that seek to address process input and output factors [25]. Whilst there is some criticism of these tools [53], they appear popular amongst the more innovative developers. This may be because those found to be in general use normally offer a framework of common principles applied as a practical process. These provide a means by which $\mathrm{KPA}$, indicators and measures match pragmatic benchmarks enabling comparisons with similar processes. From such comparative study, it is possible to make reasonable assumptions regarding recognizable best practice outcomes. This potential for greater certainty should not be underestimated because developers are constantly concerned about risk, market positioning and competition. The models offer a means to measure logically connected indicators of performance in a system and to determine the achievements of a project with the measures of success used to improve market share, unlock institutional finance and crucially potential statutory approvals.

Furthermore, the tools provide general procedures needed to ensure a development is environmentally, socially and economically sustainable. Many of the pathways within the models have evolved from an appropriate level of rigour through case study research. This ensures that the best practice standards are not biased or based on impractical levels of performance. This again may be a reason why they can be popular because some highly theoretical but possibly more rigorous tools 'are data hungry and expensive to service making them impractical in the scheme of some organizations' [25]. Interestingly, there are no fully 'international' precinct tools. Whilst the few available have major similarities in their content, they generally only operate within national or regional markets. Most are to some degree internationally recognized if only via research contact and the sharing of ideas and business interactions.

Whilst other models or tools also concentrate on the early stages of the process, most do not appear to continue monitoring the total life cycle outcomes. This is a limited and inadequate analysis of total development and property investment. It can be stated that there is also a notable research concentration on early planning and design decisions. This work often takes little regard of the postoccupancy phase of a programme reflecting the continuing fragmentation of project delivery by the development industry [49]. These are important observations if, for example, government targets regarding carbon reduction are to be achieved. To reach them, the necessary emission diminution will have to come from buildings such as the case study resort in the initial phases.

Also, the outcomes will need to be maintained and possibly improved through genuine ongoing performance results over considerable periods of time rather than non-achieved predictive wish listing at the design stage. A major postconstruction feature of the case study is the commitment to POE and crucial ongoing educational development [16]. This used a further accreditation tool that is part 


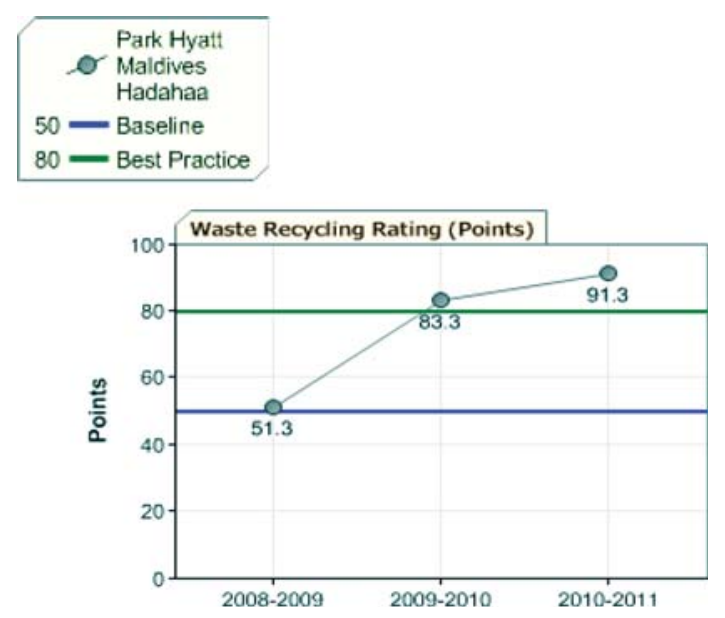

Figure 2: Setting and measuring industry base and best practice performance levels. Waste recycling rating (points) for the year 2010-2011 (1 October 2010 to 30 September 2011) was 91.3 points, which was 11.3 points better than the Best Practice level.

of the independent third-party's accreditation provision. When linked to the increasingly important area of Facilities Management [54], this long-established systematic and rigorous process [55] provides a focus on building occupants and needs and equipment and systems performance. To meet best practice operational requirements, performance levels are pragmatically set with reference to the type of activity (registered sector/s) and appropriate national and international data, which take into account social, geographical and climatic impacts (see Fig. 2).

Underwriting this postoperational process is documentary evidence that demonstrates how the project met the POE framework KPA indicator's criteria. Each fully described KPA indicator when measured and awarded demonstrates criteria fulfilment. Clearly specified, documentary evidence is required for each indicator. The POE Standard's assessment documentation also contains predictive model calculators that are used to score the performance of a project in terms of its energy efficiency, energy mix (which relates to Green House Gas emissions), and water efficiency and water source mix (which relates to optimum potable water use). The values input into these calculators from the results of the predictive modelling. When a project is assessed, it is scored in two ways: an overall score based on a summation of indicator measures points and four separate ranking scores (all out of 100) relating to results from predictive modelling.

For example, energy efficiency, greenhouse energy mix, water use efficiency and water source mix. These four ranking scores are intended to provide a more detailed indication of the projects sustainable performance in four key areas of sustainability; energy efficiency, GHG emissions, water use efficiency and optimum potable water use. These ranking scores relate to indicators and provide an indication of how well (or poorly) a project has passed (or failed) the initial predicted outcomes criteria determined by planning and design and the latter postoperational phase. The ranking scores when reported provide meaningful feedback to developers to allow early mitigation, detection and/ or enhancement of aspects of development that impact on improved ecological performance.

Results from 2009 to $2011[56,57]$ at the case study indicate that in KPA the resort exceeded industry best practice operational norms by considerable margins. This surpassing continues with further improvements seen in the latest benchmarking returns. For example, initial evaluations for 
potable water consumption were $83 \%$, recycled water $67 \%$, water savings $14 \%$ and cleaning products $16 \%$ better than industry best practice in 2009/2010. The corresponding numbers for 2010/2011 show further encouraging results (i.e. energy consumption 5\%, emissions $14 \%$ and community contribution $20 \%$ above best practice) demonstrating the efficacy of adopting integrated processbased framework models if the goal is to deliver long-term ecological performance gains and improvements.

It is worth noting in this section that another principal evaluation focus for resort developers and operators is reward and recognition. At operational level, this often needs to translate into economic returns flowing from added value decisions taken earlier in the development process. Sustainability investment comes at a cost, which from research can equal anything from a $2 \%$ to $8 \%$ increase on initial construction costs [58]. However, such simplistic equations do not truly reflect the complexity of valuing 'green' buildings. The well-known environmental and health benefits deriving from them offer predictive performance outcomes of less certainty than are possible when using life-cycle technical savings [59].

Whilst the preceding figures suggest that savings are made at the facility of more importance is the comparisons of initial investment costs in planning, design, materials, plant and equipment and the more difficult to control user responses and impacts, which reflect on income. The question here is do they equate to true in use and life-cycle cost savings and improved returns when compared with the initial cost and time plan. Returns on capital invested are a truer measure of efficacy but are often too complex for most life-cycle models. However, it is suggested that on average a $2 \%$ green design investment would generate a $20 \%$ life-cycle saving on total construction costs; ten times the initial investment [60]. Unfortunately, whilst this suggests beneficial returns for the innovative developer other research points to a lack of clarity in financial drivers and returns. This is seriously impacting on decisions linked to significant investment in sustainability. The primary cause is alluded to earlier. The result is an inability of stakeholders to accurately measure improved ecological performance or understand possible impacts upon total development value [59].

A critical element in any model is income derived from the investment decisions. Tourists still consider dominant prosaic factors such as safety, travel costs and accessibility, weather and the quality of a facility when planning holidays. Whilst it is known that there is rising demand for ecotourism, this is not significant in the growing mass tourist markets. Most do not actively inquire about a business ecological performance or sustainability practices [61-63]. Interestingly, it is the developers and operators who are increasingly showing awareness of the risks that arise from the demands for socially and environmentally responsible tourism. Whilst some of this is driven by governmental demands, it is also a search for product enhancement giving greater market penetration and potential income growth that is driving the exploration and use of certification programmes. For others, it is a need for long-term improvements in development processes and operational performance leading to industry recognition and better rewards [64].

\section{FINDINGS, KEY LESSONS AND CONCLUSIONS}

The need for this ongoing research into delivery and assessment of tourism infrastructure such as resorts and hotel is a reflection of the growing demands of one and the response of the other. Travel and tourism is the fastest growing industry worldwide. The development and allied construction industries are the major delivery platforms. Both have to respond to increasing pressures for ecologically sensitive actions particularly when operating in developing nations. On the one hand, increasing numbers of tourists demand safer, more affordable and increasingly culturally different experiences. On the other hand, governments are faced with improving the quality of life of their nation whilst protecting often unique peoples and environments. 
This case study [65] along with many others from a broader research project show how some developers are responding to the demand for balance between economic growth and environmental and social improvements. For many, the response reflects the calls for sustainable development in construction and management of travel and tourism facilities and associated infrastructure. Interestingly, this is despite the continuing confusion regarding theoretical definition and practical application. To accommodate the uncertainty generated, a simpler approach for developers is to consider risk as a better means of driving decisions. This approach has the advantage of overcoming inertia by ensuring any actions taken to evaluate the costs of mitigation or of not doing anything.

The specific study supports the growing recognition that projects need measuring in terms of their impacts and eventual performance. It also shows a critical need to eradicate or at least mitigated negative impacts by current best practice. Achievement of best practice, however, is dependent on measurable actual performance that is location specific. Of importance is that all parties to the processes involved recognize and acknowledge that only with the resulting data will critical decisions regarding sustainability and its rewards have any certainty of success. Such is the importance of this that recognition must be given concurrently, that when challenging 'business as usual' process norms that entail broad ecological agendas; this requires considerable inputs and in specific locations the implementation of innovative delivery strategies.

The ongoing collection of performance data particularly in determining baselines and industry best practices is crucial to all frameworks, models and tools. A significant strength of the BPDS performance levels is that they change over time due to continuous review particularly regarding locational variances. As more developments (many from developing nations) are accredited, so the database grows. In addition, a team of international experts who take into account 'business as usual' practice changes, equipment and facilities carries out ongoing reviews of the standards and their content. This type of review is important and reflects on critical differences between regions.

For example, the major determinant of energy consumption in resorts normally centres on accommodation, visitor infrastructure and administration. Determination of the level of usage is by the dominant climatic conditions in which the facility is located. In general, to maintain the same level of indoor comfort, facilities operating in a hot or cold climate will consume more energy than those in temperate climates. Another antithetical observation surrounds the use of water. Higher water usage in Australasia than in Europe is common. The variance on similar schemes can be as high as ten times per person per night due to greater use of fountains, pool evaporation and a tourist's personal water demands. Setting targets can be problematic if frameworks and tools use data that are single nation centric to determine performance levels. The reviewers, therefore, give regard to issues surrounding local achievable performance targets whilst still seeking to achieve sought for international advances in ecological outcomes. They also consider regulatory and general improvement trends in performance and procedures. The new certifications and reviews constantly update the levels of baseline and best practice and provide feedback to users of the standards KPA's, indicators and crucially pragmatic measures.

To deliver the deemed appropriate measures specifically developed, sustainability and ecological performance documents for a resort's planning and design and assessor inputs ensures compliance throughout the development in terms of delivery and quality. The enshrining of the documentation and the commitment of dedicated consultants aid users and maintain an important link between the developer, professionals, the building team, purchasers and other stakeholders' particularly impacted communities. These actions and others that are noted suggest that for those who wish to undertake innovative, responsible and committed approaches on their developments, they need at least to recognize the merits of an open mind when seeking to achieve sustainable outcomes. 
This particular case study also confirms the critical need for ongoing involvement between initial development progressions and associated long-term operational management practices adopted by facility managers. Discussions with the developer confirmed the high priority given to continuing performance assessment. POE as seen now takes place on a yearly basis using a further tool created specifically for travel and tourism developments. This is a result of recognizing that many sustainable inputs and their impacts take place over time. These may only come about by ongoing adjustment to aspects of the development, a phenomenon likely seen in the critical social, cultural and economic areas. In support of these findings, recognition that successful management of the postconstruction or operational phase is crucial to long-term community success. The standards used on the case study have 10 years of data collection to call on. Unlike other tools, they do not tend towards providing a range of approaches targeting 'perceived' sustainability possibilities. However, as schemes are

completed both continue to change into more accurate predictive development outcome frameworks.

Two key lessons from this particular assessment, which other developers should reflect on, were first that the resort benefited from the integration of an 'Ecological Vision'. This reflected environmental, cultural and economic sustainability. The resultant goals, aims, objectives and performance briefs, when aligned with the third-party assessment framework principles provided an opportunity to undertake an international recognized independent benchmarking and certification assessment. Secondly, considerable effort can be required to overcome problems in sourcing the supply chain with regard to appropriate green systems and equipment. The location of remote developments and adjoining communities requires companies that can properly service these projects with allowances made when assessing this aspect of developing a tourism market and subsequent offer.

Accordingly, the developer in the case study responded to the demand for tourism infrastructure delivery managed in a sustainable manner and a measured development in terms of impacts and eventual ecological performance. The resultant information and data gathered over the last 5 years is critical for assessing the original planning, design and management, decisions when seeking an assurance of successful outcomes. By challenging the norms of resort delivery and opening the planning and design to the scrutiny of an internationally recognized BPDS, it indicated a willingness to reduce if not mitigate entirely the impacts of development. The developer and the original facility operator/manager challenged business as usual processes whilst recognizing that sustainable agendas require considerable inputs. The challenge continued by the eventual operator also reflects an increasing penetration of the corporate governance of many companies responding to the growing demands for ecological sensitivity in their actions.

The project has achieved a high industry best practice assessment due in part to the measurable implementation of an innovative delivery strategy and by a long-term commitment to the resort owner and operator. This has confirmed other assessed project findings regarding the need for ongoing involvement with a development and the associated management processes. This willingness to put forward a sustainable agenda of their own making sought to recognize the relationships with clients, regulators and other stakeholders. The agendas and approaches used on the case study resulted in possibly a more effective development process that could result in better sustainability responses to the growing leisure/active tourism demands based on small islands in developing coastal regions.

\section{REFERENCES}

[1] UN World Tourism Organisation (UNWTO), 2010 International Tourism Results and Prospects for 2011, www.unwto.org, 2011 (accessed January 2011).

[2] UN World Tourism Organisation (UNWTO), Challenges and Opportunities for Tourism Development in Small Island Developing States, UNWTO: Madrid, Spain, 2012. 
[3] Boniface, B., Cooper, C. \& Cooper, R., Worldwide Destinations - The Geography of Travel and Tourism, 6th edn., Routledge: London, UK, 2012.

[4] Williams, S., Tourism Geography, 2nd edn., Routledge: London, UK, 2009.

[5] Becker, E., Overbooked: The Exploding Business of Travel and Tourism, Simon \& Schuster: London UK, 2013.

[6] TIES, Global Ecotourism Fact Sheet (Research by Canopy Development). The International Ecotourism Society, Washington, USA, www.ecotourism.org, 2006 (accessed May 2009).

[7] UNWTO, Guide for Local Authorities on Developing Sustainable Tourism - Supplementary Volume on Asia and the Pacific, Tourism and Environment Publication, World Tourism Organisation: Madrid, Spain, 1999.

[8] French, C., Craig-Smith, S. \& Collier, A., Principles of Tourism, 2nd edn., Longman: NSW, Australia, 2000.

[9] Spenceley, A., Responsible Tourism, Critical Issues for Conservation and Development, Earthscan: London, UK, 2010.

[10] Scott, D., Hall, C.M. \& Gossling, S., Tourism and Climate Change - Impacts, Adaptions and Mitigation, Touteledge: London, UK, 2012.

[11] Bijlsma, L., Coastal Zones and Small Islands, Intergovernmental Panel on Climate Change, Cambridge Press: Cambridge, UK, 1995.

[12] Intergovernmental Panel on Climate Change (IPCC). Climate Change 2001, Synthesis Report, Cambridge Press: Cambridge, UK, 2001.

[13] Creel, L., Ripple Effects: Population and Coastal Regions, Population Reference Bureau (PRB) Measure Communication: Washington DC, USA, 2003.

[14] Hague, C., The Maldives - Challenges for Sustainable Development in a Small Island State, www.cliffhague.planningresource.co.uk, 2012 (accessed February 2012).

[15] Swarbrooke, J., Sustainable Tourism Management, CABI Publishing: Oxen, UK, 2005.

[16] Moore, R., A Framework for Sustainable Development, Paper presented to the 16th Annual International Sustainable Development Research Conference May/June 2010 Kadoorie Institute The University of Hong Kong, 2010.

[17] Dodds, S. \& Kelman, I., How Climate Change is Conceived in Sustainable Tourism Policy, A Case Study of the Mediterranean Islands of Malta and Mallorca, Tourism Review International, Vol. 12, pp. 57-70, www.cognizantcommunication.com, 2008 (accessed January 2011).

[18] Scott, D., Hall, M. \& Gossling, S., International Tourism and Climate Change, Wiley Online Library, www.wiley.com, 2012 (accessed March 2012).

[19] Gortázer, L. \& Marin, C., Tourism and Sustainable Development - From Theory to Practice, The Island Experience, Consejeria de Tourismo y Transportes Gobierno de Canerias Espana, 1999.

[20] McElroy, J., Managing sustainable tourism in the small island Caribbean. The Journal of Ecological Economics, www.cep.unep.org, 2000 (accessed September 2011).

[21] Twining-Ward, L. \& Butler, R. Implementing STD on a small island: development and use of sustainable tourism development indicators in Samoa. Journal of Sustainable Tourism, 10(5), pp. 363-387, 2000. doi: http://dx.doi.org/10.1080/09669580208667174

[22] Gough, K., Bayliss-Smith, T., Connell, J. \& Mertz, O., Small island sustainability in the Pacific: introduction to the special issue. Singapore Journal of Tropical Geography, 31(1), 2010, Article first published online: 29 March 2010 Wiley (onlinelibrary.wiley.com, accessed August 2011).

[23] Nath, S., Roberts, J. \& Madhoo, Y., Saving Small Island Developing States, Environmental and Natural Resource Challenges, Commonwealth Secretariat: London, UK, 2010. 
[24] Mowforth, M. \& Munt, I., Tourism and Sustainability - Development and New Tourism in the Third World, Routledge: London, UK, 2006.

[25] Hyde, R., Moore, R., Kavanagh, L., Watt, M., Prasad, D. \& Blair, J., Steering Sustainability Indicators, Audits and Measuring Success, RMIT: NSW, Australia, Chapter 11, 2007.

[26] Marmon, A., Reflections on World Tourism Day - Theme of Tourism Responding to the Challenges of Climate Change, available at: www.maldivestourismupdate.com, 2008 (accessed November 2009).

[27] Lal, M., Harasawa, H. \& Takahashi, K., Future climate change and its impacts over small island states. Climate Research, 19(3), pp. 179-192, 2002, Inter-Research, www.int-res.com, (accessed September 2012).

[28] Picard, D. \& Robinson, M., Festivals, Tourism and Social Change: Remaking Worlds, (Tourism and Cultural Change), Channel View Publications: Clevedon, UK, 2006.

[29] Outreach, SIDS Left Behind, Outreach 99 UN CSD Volume 4 Issue 15, UNED-UK: London, UK, 1999.

[30] Dodds, R., Malta's tourism policy - standing still or advancing toward sustainability. Island Studies Journal, 2(1), 2007, pp. 47-66, Institute of Island Studies, University of Prince Edward Island, Canada.

[31] Connell, J., Pacific islands in the global economy: paradoxes of migration and culture. Singapore Journal of Tropical Geography, 31, pp. 115-129, 2010, NUS and Blackwell Publishing, Singapore, Asia. doi: http://dx.doi.org/10.1111/j.1467-9493.2010.00387.x

[32] Moore, R., Another Tool - Paper presented to ANZAScA Conference Wellington New Zealand, 2006.

[33] Bass, S. \& Dalal-Clayton, B., Small Island States and Sustainable Development - Strategic Issues and Experience, Environmental Planning Issues No: 8, Environmental Planning Group, International Institute for Environment and Development, London UK, 1995.

[34] Huffadine, M., Resort Design - Planning, Architecture and Interiors, McGraw-Hill: London, UK, 1999.

[35] Sheldon, P., The Challenges to Sustainability in Island Tourism, Occasional Paper 2005-01, School of Travel Industry Management, University of Hawaii, USA, 2005.

[36] Baker, S., Sustainable Development, Routledge: London, UK, 2006.

[37] Birkeland, J., Positive Development, from Vicious Circles to Virtuous Cycles - Through Built Environment Design, Earthscan: London, UK, 2008.

[38] Thompson, P., What sustainability is (and what it is not) (Chapter 1). Pragmatic Sustainability, Theoretical and Practical Tools, 2nd edn., ed. S. Moore, Routledge: London, UK, 2010.

[39] Bell, S. \& Morse, S., Sustainability Indicators - Measuring the Immeasurable, Earthscan: London, UK, 2008.

[40] Williams, A., The Enemies of Progress - Dangers of Sustainability (Societas), Imprint Academic: Exeter, UK, 2010.

[41] Moore, R., Integration of an 'Ecological Vision' on a Small Coral Island, Paper for Sustainable Tourism - Issues, Debates and Challenges Conference April 2010 Crete and Santorini Greece, 2010.

[42] Baud-Bovy, M. \& Lawson, F., Tourism and Recreation, Handbook of Planning and Design, Architectural Press: Oxford, UK, 1998.

[43] Sweeting, J. \& Sweeting, A., A Practical Guide to Good Practice in Managing Environmental and Social Issues in the Accommodation Sector, Centre for Environmental Leadership in Business, available at: www.celb.org, 2003 (accessed May 2008). 
[44] Moore, R. Ed., Hyde, R., Kavanagh, L., Schiantez, K., Prasad, D., Blair, J., Watt, M., Bayada, B. \& Hair, A., The Case Studies - Using a Planning and Design Standard on Neighbourhoods and Precincts, STCRC Griffiths University Queensland Australia, 2009.

[45] Rey-Valette, H., Laloe, F. \& Le Fur, J., Introduction to the issue concerning the use of sustainable development indicators. International Journal Sustainable Development, 10(1-2), 2007.

[46] Yin, R., Case Study Research - Design and Methods, 4th edn., Applied Social Research Method Series Vol. 5, Sage Publications: California, USA, 2003.

[47] Kathan, C., The Design of the Study and Case Selection, The University of Groningen, Netherlands, available at: http://dissertations.ub.rug.nl, 2008 (accessed April 2008).

[48] Moore, R., Kavanagh, L. \& Hyde, R., Using Case Studies to Evaluate the Effectiveness of an Environmental Assessment Tool for the Planning and Design of Precincts, Paper presented to Subtropical Cities Conference Brisbane QLD Australia, 2006.

[49] Moore, R., Alila Villas Hadadaa Maldives, Case Study Report for EC3 Global Green Globe Brisbane QLD Australia, available at: www.earthcheck.org, 2008.

[50] Moore, R. (ed.) Green Globe Building Planning and Design Standard, EC3 Global (Earthcheck), available at: www.earthcheck.org, 2008.

[51] Gardiner, P., Project Management - A Strategic Planning Approach, Palgrave MacMillan: London, UK, 2005.

[52] Stasinopoulos, P., Smith, M., Hargroves, K. \& Desha, C., Whole Systems Design - An Integrated Approach to Sustainable Engineering, Earthscan: London, UK, 2009.

[53] Mawhinney, M., Sustainable Development - Understanding the Green Debates, Blackwell Science: London, UK, 2002.

[54] Park, A., Facilities Management - An Explanation, 2nd edn., Palgrave: London, UK, 1998.

[55] Lewis, A., Rationalising a tourism curriculum for sustainable tourism development in small island states: a stakeholder perspective. Journal of Hospitality, Leisure and Tourism Education, 4(2), available at: www.hist.heacademy.ac.uk, 2005 (accessed September 2011).

[56] Preiser, W., Rabinowitz, H. \& White, E., Post-Occupancy Evaluation, Van Nostrand Reinhold: New York, USA, 1998.

[57] EC3 Global, Benchmarking Assessment Report - Villas Benchmarking, Alila Villas Hadahaa Maldives, EC3 Global (Earthcheck) Brisbane Australia (available at: www.ec3global.com), 2011.

[58] EC3 Global, Benchmarking Assessment Report - Villas Benchmarking, Alila Villas Hadahaa Maldives, EC3 Global (Earthcheck) Brisbane Australia (available at: www.ec3global.com), 2012.

[59] Kats G., (ed.) The Costs and Financial Benefits of Green Buildings - A Report to California's Sustainable Buildings Task Force, California, USA, 2003.

[60] Bowman, R. \& Wills, J., Valuing Green - How Green Buildings Affect Property Values and Getting the Valuation Method Right. Green Building Council of Australia, Sydney, Australia, 2008.

[61] Meyers, G. \& Reed, R., Insights into Sustainability and Valuations - Evidence from Australia and New Zealand, European Real Estate Society Conference, Stockholm, Sweden, 2009.

[62] Chafe, Z. \& Honey, M., Consumer Demand and Operator Support for Socially and Environmentally Responsible Tourism, CESD/TIES Working Paper No 4, Revised April 2005, Center on Ecotourism and Sustainable Development and The Ecotourism Society USA, 2005.

[63] Yunhi, K. \& Heesup, H., Intention to pay conventional-hotel prices at a green hotel - a modification of the theory of planned behaviour. Journal of Sustainable Tourism, 18(8), 2010, available at: www.tandfonline.com, (accessed July 2010). 
[64] Moore, R., Building Green - The Future of Tourism Accommodation, The 'Green Tourism Design Workshop' - June, 2008, Western Australia Tourism Board, WA, Australia, 2008.

[65] Moore, R., WIT Transactions on Ecology and the Environment, Vol. 166, WIT Press: Southampton, www.witpress.com, 2012, ISSN 1743-3541 (on-line) doi: 10.2495/ISLANDS120091. doi: http://dx.doi.org/10.2495/ISLANDS120091 